\title{
AFRICAN PHILOSOPHY IN THE EYES OF THE WEST ${ }^{1}$
}

\section{Edwin Etieyibo}

Department of Philosophy, School of Social Sciences

University of the Witwatersrand

edwin.etieyibo@gmail.com

\section{ABSTRACT}

In this paper I unpack some nuanced aspects of cultural imperialism against the backdrop of Du Bois's analysis in The souls of black folk, dealing with the confrontation of African Americans or blacks by the other (the West). My aim is to gesture towards how certain ways of doing African philosophy can be considered culturally imperialistic. I seek to illustrate one culturally imperialistic way of doing African philosophy by discussing Thaddeus Metz's brilliant presentation of Ubuntu as an African moral theory. My motivation is to suggest along the way that his version of an Ubuntu-inspired moral theory seems to me a paradigmatic case of one such way.

Keywords: Cultural imperialism; African philosophy; Africa; African; Ubuntu; West; Western liberal paradigm; liberalism; communitarianism; Du Bois

\section{INTRODUCTION}

The literature is replete with debates and discourses on values and ethics in general and human rights in Africa, in particular. In addition, and specifically in recent

1 The title "African philosophy in the eyes of the West" is a modification of the one that I presented at the 20th Annual Conference of the ISAPS, Fort Hare, East London (30-31 May 2014), which had the title "Cultural imperialism and African philosophy". Although both papers deal with the same central, namely, examining or viewing African philosophy from the standpoint of the West, the former title better captures this confrontation in the way that is suggested by Du Bois's The souls of black folk, hence the title modification.

\section{UNISA $\cong$}


time, the issue of Ubuntu has caught the attention of scholars. On his part and as an important contributor in the debate on African ethics, Thaddeus Metz has thrown open a new horizon which has drawn different responses from scholars, most of whom, contra Metz, have suggested alternative approaches to the issue.

This paper adds to the debate and complements existing literature, not by suggesting any competing alternative to Metz's version of an Ubuntu-inspired moral theory, but by taking a therapeutic dimension to introduce a diagnostic initiative into the debate through pointing out the weaknesses of Metz's position and methodology. In making inroads into Metz's articulation of Ubuntu moral theory, I will begin with Du Bois's articulation of cultural imperialism. The importance of my engagement with $\mathrm{Du}$ Bois is significant because his analysis of the confrontation of African Americans by whites has connections to the way that Metz brings some Western ideas into dialogue and confrontation with African philosophy, namely, he sets up Africa against the West with the way he cashes out some facets of Ubuntu in terms of certain aspects of Western thought.

When Du Bois wrote The souls of black folk, his analysis of life behind the veil of race, the resulting "double-consciousness", and "the sense of always looking at one's self through the eyes of others" referred primarily to the experiences and condition of African Americans or blacks. Of course, his analysis can be extended to others in similar conditions and with contiguous experiences, particularly to Africans in the era of colonialism and post-colonialism insofar as a burden is placed upon them to define themselves through the eyes of the West. The veil of race that results in "double-consciousness" falls within the ambit of cultural imperialism, where cultural imperialism concerns the practice of promoting a supposedly more "powerful culture" over another that is considered "less powerful". In this relationship the former is considered "superior" and the latter "inferior", where superiority and inferiority may be taken to connote desirability and undesirability, respectively.

In Du Bois's analysis the "other" that confronts the African American is the West. In the spirit of his exploration I am extending my discussion in this paper to some characterisation of the cultures, values and trends of thought that are predominant in sub-Saharan Africa. Insofar as I am making this extension one can appropriately talk of African philosophy in the eyes of the West, just in case the characterisation constitutes some confrontation between the African condition and experiences and the West. My aim in this paper is to unpack some nuanced aspects of cultural imperialism and to gesture towards how certain ways of doing African philosophy can be considered culturally imperialistic. I seek to illustrate one culturally imperialistic way of doing African philosophy by discussing Thaddeus Metz's brilliant presentation of Ubuntu as an African moral theory. My overall interest is to point our attention to subtle forms of culturally imperialistic tendencies that may appear in our thinking and ways of doing and presenting African philosophy and to 
suggest that Metz's version of an Ubuntu-inspired moral theory is representative or paradigmatic of one such approach.

\section{SOME PRELIMINARIES}

Before I proceed, some ground clearing will be important. I would like to clear up a few things regarding my use of the terms "universalist", "particularist" and the "West".

My use of "universalist" and "particularist" draws first and foremost on the tradition in African philosophy within the context of the debate, some decades ago, about the existence or otherwise of African philosophy. Universalist refers to members of the universalist school who hold that in terms of methodology, philosophy should be the same in Western and African discourses, namely, universal, systematic, analytic, rational, scientific and rigorous. In contrast, particularist refers to those that belong to the particularist school, who contend that when it comes to reality, different cultures have different explanatory frameworks and that Africans have a philosophy that is essentially different from other philosophies. ${ }^{2}$

As for the "West", I will be using it in this paper to generally designate a "geographical point" or a "psychological attitude". In respect of geography one may refer to someone as being "from the West" if such a person is geographically located in the West, that is, he or she originates from any part of the Western world or society. Therefore, a person that hails from say, Germany, Canada or Australia is, according to this rendition, from the West. Such a person is a "geographical member" of the West or Western world. The geographical usage of the West is different from that which designates some psychological attitude. In the latter sense one may designate someone as Western if such a person is sympathetic to Western culture or paradigms in addition to counting the world and life-experiences of non-Western people as inferior or less desirable on the basis of such culture or paradigms. For want of a better word, let us call such a person a "psychological associate" of the Western world or West.

2 It must be pointed out that just because one rejects universalism in favour of particularism does not mean that the particularist is a cultural relativist. A particularist could in some way be a pluralist. That is, particularism could be said to reflect the pluralism and heterogeneity of cultural knowledge forms, ideas and traditions. It may be the case that the position of the particularist school commits it to cultural relativism. Whether it does or does not is not germane to the direction of this paper. For some discussions on the clash between the universalist and particularist schools see Momoh, CS. 1985: 73-104; Van Hook, J.M. 1997: 385-396; Hesein, I. 2010: 15-21. 
We might take the Western psychological associate as a "Western universalist" (WU) insofar as she is committed to defending a one "superior" Western paradigm. ${ }^{3}$ My interest in the West in this paper is the WU. In general, the universalist lives by a mindset that psychologically commits her to evaluating the merits of other cultures and life-experiences by the paradigm of her own culture or a one "superior" paradigm. As a particular instantiation of the universalist, a WU takes a one "superior" Western paradigm to exist and commits herself to evaluating the merits of other cultures and life-experiences in terms of this one "superior" Western paradigm. ${ }^{4}$

A geographical member of the West is not necessarily a WU. She is a WU insofar as she is also a psychological associate. This means that one may for example, hail from Germany, Canada or Australia and yet not be a WU if such a person neither believes in a one "superior" Western paradigm, nor is committed to evaluating the merits of other cultures and life-experiences in terms of this one "superior" Western paradigm. Also, a psychological associate of a particular place is not necessarily a WU even though she may be a universalist, namely, believes in a one superior paradigm. A person that takes a one "superior" Asian or African, Arabian or Caribbean paradigm to exist and commits herself to evaluating the merits of other cultures and life-experiences in terms of this one "superior" paradigm, is although a psychological associate, not a WU. Rather, she is an Asian or African, Arabian or Caribbean universalist. Furthermore, one may be a psychological associate, and consequently, a WU even though she is not a geographical member of the West. So, a person from Nigeria, Jamaica or Philippines may be a WU if she takes a one "superior" Western paradigm to exist and commits herself to evaluating the merits of other cultures and life-experiences in terms of this one "superior" Western paradigm.

As I will be arguing in the paper, Metz's version of an Ubuntu-inspired moral theory suggests that he is a WU. What makes Metz's presentation culturally imperialistic is that it is hardly ever in question that it unpretentiously confronts African philosophy with some of the ideals of the West or caches out some aspects of Ubuntu in terms of certain aspects of Western thought. Particularly, he incorporates some Western ideals, which he considers desirable, into his version of an Ubuntuinspired moral theory. The subtlety and mute suggestion in Metz's articulation of Ubuntu as an African moral theory is this: to be respectable and desirable a plausible Ubuntu moral theory is to be aligned in such a way so as to fit with some "superior"

3 The term Western universalist seems to be in order, given that there can also exist a non-Western universalist, such as an African universalist or Asian universalist, namely, those who are committed to defending a one "superior" African or Asian paradigm.

4 On this presentation, even an African can be a WU. Indeed, during the early part of the clash between the universalist and particularist schools the African logical neo-positivists qua universalists were taken to be "biased towards the West". It is important to note that many of the African logical neo-positivists were black and Africans. 
paradigm of the West, namely, the liberal paradigm. Significantly, he does this not with the intention to denigrate. ${ }^{5}$ My use of the phrase "not with the intention" is deliberate and very important. This is because I do not think that in presenting his rendition of Ubuntu which incorporates some Western paradigm, Metz purposefully sought to depreciate, as inferior, Ubuntu or African philosophy or African cultures and life-experiences.

\section{DU BOIS AND CULTURAL IMPERIALISM}

$\mathrm{Du}$ Bois can be considered as one among the many of the early and foremost panAfricanist intellectuals. He had a long career as a teacher, sociologist, historian, civil rights activist, pan-Africanist, author and editor. Du Bois was born in Great Barrington, Massachusetts and he wrote extensively. Some of the most prominent of his works include Black reconstruction in America (1935), and The souls of black folk (1903). In Black reconstruction in America Du Bois was critical of the dominant view that blacks were responsible for the failures of the Reconstruction era. In The souls of black folk he discusses issues that revolve around the problems encountered by the post-emancipated African Americans.

$\mathrm{Du}$ Bois's incursion into the realm of cultural imperialism is captured in The souls of black folk, where he presents some insightful summary, discussion and analysis of the experiences and condition of post-emancipated African Americans. The early chapters deal with a sketch and analysis of the spiritual world in which many African Americans live in and strive. In subsequent chapters Du Bois shows what emancipation meant to African Americans, and what its aftermath was. And in later chapters he points out the slow rise of personal leadership in the African American community, and criticises the leader (namely, Booker T. Washington) whom he thinks bears the chief burden and responsibility of the problem of race of the African American. In the final chapters Du Bois concludes the book by focusing on how racial prejudice impacts individuals and provides an outline of the two worlds within and without the veil (of race).

The souls of black folk is an important work in African-American literary history in particular and on issues of cultural imperialism that confront black (or African) people the world over in general. This is particularly so because Du Bois uses it to demonstrate how racial prejudice impacts blacks and to decry the intellectual and cultural imperialism which the post-emancipated black Americans suffer, particularly in being viewed and judged through Western eyes and lenses. Du Bois's position on the impact of the intellectual and cultural imperialism on blacks can be summed up

5 I am prepared to assume that Metz has the best of intentions. But perhaps, some might think that in his articulation he does so with the intention to denigrate. However, whether he does have the intention to denigrate or not, is not relevant to my presentation and position. 
in his claim that: "The problem of the twentieth century is the problem of the colorline, - the relation of the darker to the lighter races of men in Asia and Africa, in America and the islands of the sea" (1903: 16).

In being viewed through the prism of the world, especially the world of the West the African American is plunged into a sense of double-consciousness which denies her the possession of any consciousness. That is simply put, the confrontation by the West of the African American results in a double self that seeks to merge into a truer self - a truer self that the individual cannot get a hold of. Du Bois puts it this way: this lack or loss of consciousness for the "Negro" constitutes the history of the black American, "which is the history of this strife - this longing to attain self-conscious manhood, to merge his double self into a better and truer self" (1903: 9). More worrying is that although the African American desires the merger of her double self, she wishes to retain her past (which is not fully there), namely, not wanting "the older selves to be lost" (Du Bois 1903: 9). ${ }^{6}$

$\mathrm{Du}$ Bois's discussion of the problems encountered by the post-emancipated African Americans in The souls of black folk and the relationship of this to cultural imperialism, sets the tone for us in trying to conceptualise and explore the question of the presentation of African philosophy, in particular the issue of how African philosophy is viewed by the West. While on the one hand, one would say that $\mathrm{Du}$ Bois's idea of double-consciousness means that the African or black person in general is experiencing what might be called a cultural lacuna, on the other hand, she can be said to be intellectually subjected to the experience of the other, the West. This subjection requires her to prove to the world, specifically the West, that she is human. It requires also that she demonstrates that her culture, life-experiences and paradigms are desirable and not inferior to those of the West.

In other words, the African is presented as an inferior subject and her humanity or personhood is measured only through her relationship with the West. In terms of the problem of double-consciousness the African has to be alienated, namely, reject herself, her identity, and acquire the humanisation narratives of the West in order to be accepted. This has implications both in terms of teleological aspirations and African philosophy. Regarding the former, the ambitions of the African become, in the words of Appiah (1992: 95-96), "entrapped within the Western cultural matrix we affect to dispute". As for the latter, given that African philosophy is measured in terms of Western philosophy, the acceptance and legitimacy of its philosophical procedures are determined by the Western interrogator. This is what Michael Onyebuchi Eze (2010a; 2010b) calls the "colonization of subjectivity", where African philosophy is created to satisfy the intellectual curiosity of the Westerner who asked the question, "is there an African philosophy?"; and where the African intellectual is still and constantly being invented and conceived by the Western coloniser.

6 For a lengthier discussion of Du Bois's presentation of cultural imperialism in the context of race, see Etieyibo, E (2015: 147-170). 


\section{THE WU AS A PSYCHOLOGICAL ASSOCIATE}

Recall that the WU is one who takes a one "superior" Western paradigm to exist and commits herself to evaluating the merits of other cultures and life-experiences in terms of this one "superior" Western paradigm. The WU reminds us of members of the universalist school in African philosophy during the debate about its existence or non-existence. ${ }^{7}$

The WU accepts a superior Western cultural paradigm and judges other cultures as inferior to it. Relatedly, those who belong to the universalist school in African philosophy foist a one universal Western method of philosophy on African philosophy. Insofar as both take a universalist view of cultural experiences (a view that is biased towards the West) they are the same. Within the context of cultural imperialism one might call them imperialist and non-WU or proponents of the particularist school anti-imperialist, simply because at the heart of their positions is the view about how to place a particular cultural paradigm, namely African philosophy relative to the West or Western philosophy. ${ }^{8}$

There may be many motivations behind the position of the WU or those that belong to the universalist school. Some may be motivated by their fascination with the West, its history and development. Others may sincerely believe that in tracing the history of ideas the West has got it right in many aspects, particularly in respect of certain cultural paradigms. Yet others may be motivated by what Oguejiofor (2007: 31-36) calls the image of the philosopher. His point is that because the WU has an image of the philosopher as a wise and perceptive thinker who has the ability to exceed the reality that the ordinary person or majority of people can see and fathom, it has generally adopted a stance that seems dismissive of a genuinely African thought system. ${ }^{9}$ We shall call the cultural imperialists who are motivated in the first case the "infrastructure admirer", those in the second case the "intellectual admirer" and those in the third case the "image admirer". In arguing that Metz is a WU, namely a psychological associate, I will be suggesting that he is an "intellectual admirer"

7 See the section on "Some preliminaries" for the motivation driving the universalist school.

8 The importance of the question of placement and the significance of the debate about African philosophy can be seen from the fact that much of the early literature on African philosophy was focused on the questions: "Is there an African philosophy?", "What is the nature of African philosophy?" and "How should African philosophy be defined?" See for example, Diop, C.A. and Okpewho, O.O. 1981: 587-602; Momoh, C.S. 1985: 73-104; Onyewuenyi, I.C. 1991: 29-46; Oruka, H.O. 1975: 44-55; Wiredu, K. 1972: 3-13.

9 And if one takes Bruce Janz's (2007: 689) claim that “...questions about African philosophy's existence by non-Africans have often amounted to an implicit dismissal of Africa", then on a radical interpretation of WU's cultural imperialism one might even worry whether WU's attempt to impose on African worldview a Western paradigm is not indirectly a denigration of Africa and Africans. This radical interpretation takes the WU not as an "intellectual admirer" but a cultural imperialistic colonialist. 
insofar as he does not intentionally try to denigrate or depreciate African cultures and life-experiences in his alignment of Ubuntu with some "superior" Western paradigm.

\section{METZ'S UBUNTU AS AN AFRICAN MORAL THEORY}

In the article "Toward an African moral theory" Metz engages in an analytic normative ethical theorising whereby he presents a brilliant and forceful account of Ubuntu as an African moral theory. Metz presents his motivations for this project in these simple terms: to "construct an African theory of right action with the hope of developing a principle that sub-Saharan Africans ought to believe, given adherence to claims they typically deem to be less controversial than it" (2007a: 322). That is, he will attempt to capture what counts as mere tendencies or recurrent themes that are found in sub-Saharan Africa in establishing a theory of rightness (Metz 2007b: 375). These tendencies or themes will be rationally reconstructed as primarily those "values associated with talk of 'ubuntu' and cognate terms that are prevalent among sub-Saharan Africans" (Metz 2007a: 322).

In Metz's view, this project is necessary because:

In the literature on African ethics, one finds relatively little that consists of normative theorization with regard to right action, that is, the articulation and justification of a comprehensive, basic norm that is intended to account for what all permissible acts have in common as distinct from impermissible ones. (2007a: 321)

The project is laudable and one that I think is important, not the least because it provides a moral theory that could be compared, in Metz's words, "to dominant Western theories such as Hobbesian egoism or Kantian respect for persons" (Metz 2007a: 321), but also that it opens up the space for a rigorous debate on African ethics in general and Ubuntu in particular.

Since his first articulation of Ubuntu in "Toward an African moral theory" the theory has been developed and modified to include an account of human dignity, human rights, and so forth. Some of the developments come as a result of Metz's attempt to apply Ubuntu to a number of issues such as capital punishment, the environment, bioethics, and human rights. ${ }^{10}$ It is from this original presentation of Ubuntu and its modification and development that I shall seek to peel out the thesis that Metz's presentation of Ubuntu as an African moral theory is culturally imperialistic and paradigmatic of ways in which African philosophy is made to confront the West.

Metz begins his project on Ubuntu by critically surveying some of the available literature on African philosophy. This is with the aim of articulating and justifying

10 For the development in Metz's original expression of Ubuntu moral theory see Metz, T. 2007b: 369-387; Metz, T. 2010a: 81-99; Metz, T. 2010b: 49-58; Metz, T. 2011: 532-59; Metz, T. 2012a: 19-37; Metz, T. 2012b: 61-83; Metz, T. 2014: 131-51. 
a single moral principle that is faithful to tendencies or recurrent themes and values found in sub-Saharan Africa. Since he takes the tendencies or recurrent themes and values to be associated with talk of Ubuntu and cognate terms that are prevalent among sub-Saharan Africans, he explores the term Ubuntu and the associated aphorism "a person is a person through other persons". After reflecting on six expressions of this maxim or competing theoretical interpretations of Ubuntu in the literature as an ethical principle, Metz settles for one that, in his view, is the "most promising theoretical formulation of an African ethic to be found in the literature" (Metz 2007a: 334). The single principle is this: "an action is right just insofar as it produces harmony and reduces discord; an act is wrong to the extent that it fails to develop community" (Metz 2007a: 334).

Why is this the most promising principle or account of Ubuntu? It is because, according to Metz, it has the "potential to account for all the intuitions or considered moral judgments" - either those commonly accepted only by adherents of Ubuntu or by "both adherents of ubuntu and Western people in modern, industrialized, constitutional democracies" - that he discusses on pages 324-328 of the article quoted above (Metz 2007a: 334).

Metz acknowledges that although this account of Ubuntu has the potential to account for all the intuitions, it is not particularly well developed in its current form. It is too vague in respect of the fundamental requirement to promote harmony and to prevent discord. That is, it is too imprecise; metaphorical in the sense that it does not properly allow us to contextualise actions that promote harmony or lead to discord. As part of his way of rendering it less nebulous, he drapes it with some specification by attempting some clarification. The clarification does two things. Firstly, it explicitly teases out what Metz considers to be the aim of morality, which according to him is not individual well-being or self-realisation. He notes: "As opposed to well-being or self-realization, this account of ubuntu posits certain relationships as constitutive of the good that a moral agent ought to promote. What is right is what connects people together; what separates people is wrong" (Metz 2007a: 334). Secondly, it unambiguously highlights the need to introduce some delimitation mechanism into the Ubuntu project. The delimitation mechanism is a deontological constraint, which will circumscribe both theoretically and practically the concept of harmony and the fostering of relationships that are embedded in it.

With respect to the first clarification the individual qua a moral agent is forbidden to promote any fundamental moral value that is self-regarding, i.e. value that is internal to the individual. Rather, she ought to promote some value that is "other regarding", namely, the value that inheres in certain kinds of relationships. It is this first clarification that explicitly brings out the communitarian element of Metz's Ubuntu, where the individual is morally commanded not to keep an eye on herself or the autonomous self, but on relationships - the community. On the latter clarification, we are presented with the deontological constraint of this obligation. 
Why is the deontological constraint warranted? In Metz's view it is necessary in order to ensure that the moral agent in following through her obligation to "prize" and "honour" harmonious relationships, does not sacrifice individual freedom and other basic human rights. In "Ubuntu as a moral theory and human rights in South Africa", Metz cautions, "A moral theory that focuses exclusively on promoting good outcomes however one can, has notorious difficulty in accounting for an individual right to life, among other human rights" (2011: 540). It is this second clarification, the introduction of the deontological constraint, that betrays Metz's cultural imperialistic tendencies.

\section{METZ'S VERSION OF AN UBUNTU-INSPIRED MORAL THEORY AS CULTURALLY IMPERIALISTIC}

The charge that Metz's presentation of Ubuntu is culturally imperialistic would be unwarranted, were Metz to stop short of introducing the deontological constraint in his theory of Ubuntu. Since I am teasing out this culturally imperialistic element from the introduction of the deontological constraint, I would like to focus a bit on it. We have already seen part of the reason why Metz thinks that the deontological constraint is necessary. Given that the promotion of certain kinds of relationships may sometimes justify sacrificing individual freedom and other basic human rights, the delimitation, in Metz's view, of this obligation by the deontological constraint, is warranted. Using a famous example that critics have often used to vilify utilitarianism, Metz directs our attention as to why a moral theory that does not take human rights seriously may not only be problematic, but also runs into serious difficulties.

[A]n instruction to promote as many communal relationships as one can in the long run, would permit a doctor to kill an innocent, relatively healthy individual and distribute her harvested organs to three others who would otherwise die without them, supposing there would indeed be more of such relationships realised in the long term. A moral theory that focuses exclusively on promoting good outcomes, however one can (which is teleological), has notorious difficulty in accounting for an individual right to life, among other basic rights (Metz 2011: 540).

From Metz's vantage point, one of the serious difficulties that Ubuntu moral theory will run into is the charge of collectivism, namely the criticism of being uncompromising, majoritarian, or sacrificing the individual for society or the community. In his view, his version of an Ubuntu-inspired moral theory is impervious to this charge and criticism since the deontological constraint makes it to be compatible with the value of individual freedom that is among the most promising ideals in the liberal tradition (2011: 533). On this ground, Metz's reasoning appears then to be that the deontological constraint is necessary if Ubuntu as a moral theory 
is to be attractive and desirable. To be an authentic moral theory and be desirable, it has to be compatible with a certain paradigm - the value and ideals of individual freedom and rights (of the liberal tradition). ${ }^{11}$

Since liberalism or the liberal paradigm is generally taken to be opposed to communitarianism or the communitarian paradigm, it is important to investigate more deeply Metz's version of an Ubuntu-inspired moral theory in the context of its avowed communitarian commitment and supposed alignment with the liberal paradigm. Crucially, we wish to ask, how can Metz's Ubuntu account possibly be communitarian and yet consistent with the value of individual freedom that is among the most promising ideals in the liberal tradition? ${ }^{12}$ Happily, an incursion into this sort of investigation and questioning has been done by Anthony Oyowe (2013). Since I have no desire to "reinvent the wheel" I will appropriate some of Oyowe's exploration, as I seek to make the case that Metz's version of Ubuntu is culturally imperialistic.

In the article, "Strange bedfellows: Rethinking Ubuntu and human rights in South Africa", Oyowe (2013) argues, convincingly, in my view, that Metz's Ubuntu project fails in a number of areas: (a) "that individual freedom and rights can be successfully grounded in a moral theory that already regards some extrinsic value (that is, communal harmony) as the most fundamental moral value; (b) that "Metz's attempt to ground individual human rights in his Ubuntu moral theory raises the problem of where the fundamental value lies in his theory"; (c) that " in seeking to integrate two potentially-conflicting and non-instrumental values in his theory, Metz

11 I get Metz's motivation in desiring to present an account of Ubuntu that is compatible with the value of individual freedom and rights. After all, we live in an age in which "individual freedom", "choice", "human rights" constitute some of the buzzwords in and that revolve around democracies, constitutionalism and laws of nations, and international relations between nationstates. Because of this, an individual or a nation or a moral theory may seem to lack respect and be denigrated if such an individual or nation or moral theory fails to seriously take into account these buzzwords. This is similar to the way in which modern governments or regimes present themselves as democratic, even if they are not. One motivation for doing this would be to avoid a pariah-status or other isolationist consequences from the international community, just in case such a government is construed as undemocratic.

12 It must be pointed out that it is irrelevant to my criticism of Metz concerning whether he believes the good should be prioritised over the right or whether he thinks that Ubuntu deals particularly with the right and not the good. Of course, in "Ethics in Africa and in Aristotle: some points of contrast" (Metz 2012c) he argues that characteristic African values are "exclusively 'communitarian' and inconsistent with some core 'individualist' elements of Aristotle's ethics" (2012b: 99-117). However, irrespective of what he says here or does elsewhere, insofar as he grounds his version of an Ubuntu-inspired moral theory on the deontological constraint, a constraint that forbids the sacrificing of individual freedom and rights in the pursuit of some communal values of harmony and relationships, he prizes the liberal paradigm (which values individual rights) over the communitarian paradigm (that values communal rights). 
substantially modifies his original Ubuntu ethical principle in such a way that the communitarian/Ubuntu status of the theory is undermined"; (d) that "even if Metz's theory were sufficiently communitarian/Ubuntu-like, it could not possibly ground individual freedom as a non-instrumental value" (2013: 103-124).

I will not examine all of these theses but I want to explore two related ideas that arise from them. The first idea is that of the relationship between individual freedom and community or communal harmony, and the second is the idea of double values in Metz's Ubuntu. The first idea emerges from thesis (a) - the claim that individual freedom and rights can be successfully grounded in a moral theory that already regards some extrinsic value (that is, communal harmony) as the most fundamental moral value. The second idea emerges from thesis (c) - the claim that in seeking to integrate two potentially-conflicting and non-instrumental values in his theory, Metz substantially modifies his original Ubuntu ethical principle in such a way that the communitarian/Ubuntu status of the theory is undermined. I begin with the first.

One big divide in moral and political philosophy is the divide between liberals and communitarians. The divide is not brought about by practical or pragmatic reasons. The divide is brought about by intellectual posturing. Simply put, by liberals or liberalism and communitarians or communitarianism adhering to different paradigms and conception of the self. Liberals or liberalism defend individual rights and freedom, and they have a view of the self as constituted by nothing other than itself. This is the view of the self that Charles Taylor (1985) calls an atomistic view of the self. That is, the view that individuals are self-sufficient and may develop and exercise their capacities qua human beings independently of (any) society, ${ }^{13}$ or what Michael Sandel (1992) calls an unencumbered and unembedded self, namely, the putting of a distance between the self and its experiences, aims and ends. Simply put, it is a view that "rules out the possibility of...constitutive ends", that takes selves as "free to join in voluntary association with others and only capable of community not in the constitutive sense but in the cooperative sense" (Sandel 1992: 18-19). This is contrasted with the view of the self that communitarians or communitarianism generally hold; a view of the self that is non-atomistic and that is encumbered and embedded. An encumbered and embedded self is one that stands not at a distance in terms of its relations to other things, but with them; it is a self with other selves.

This divide has led to charges being traded by liberals and communitarians. While liberals criticise communitarians as being collectivist, majoritarian and totalitarian, and of holding a view of the self and community that fails to take seriously individual freedoms and human rights, communitarians criticise liberals of defending a view

13 Taylor not only criticises the atomistic view of the self, he defends as well the Aristotelian view that "Man is a social animal, indeed a political animal, because he is not self-sufficient alone, and in an important sense is not self-sufficient outside a polis." He develops this view and his objection to the atomistic view that "men are self-sufficient outside of society" in an influential essay titled, "Atomism". See Taylor 1985: 187-210. 
of the self that is deficient and being too thin to offer a robust moral ideal or sustain a rich conception of a good life for human beings. ${ }^{14}$ Clearly then, on this divide between liberals or liberalism and communitarians or communitarianism, Metz's presentation of his version of an Ubuntu-inspired moral theory as communitarian and yet liberal seems problematic, and to say the least, intriguing and intellectually unviable. On this distinction between the encumbered and unnumbered self in relation to liberalism and communitarianism, the liberal paradigm takes the right to be prior to or independent of any conception of the good while the communitarian paradigm takes the good to be prior to the right. ${ }^{15}$

To take the right to be prior to the good is to give priority to individual freedom and rights; and to take the good to be prior to the right is to give priority to the values and interests of the community. Therefore, one would say that a moral theory that is adequately communitarian or accepts the communitarian paradigm, is one that captures the basic tenets of communitarianism - tenets such as taking the individual or self to be necessarily embedded in a network of relationships (the community) or the foundational claim about the causal dependence of the individual on the community (Oyowe 2013: 105). Simply put, a communitarian moral theory will give priority to the values and interests of the community over those of the individual, and may allow (as posited above by Metz 2011: 540) "a doctor to kill an innocent, relatively healthy individual and distribute her harvested organs to three others who would otherwise die without them, supposing there would indeed be more of such relationships realised in the long term". But this is exactly what the deontological constraint in Metz's version of an Ubuntu-inspired moral theory forbids and seeks to prevent. Therefore, it is difficult to see how Metz's Ubuntu account can possibly give rein to the value of individual freedom and human rights and yet be genuinely communitarian.

I now come to the second idea - that of double values in Metz's Ubuntu moral theory. In exploring this idea I will begin with a long quote from Oyowe (2013), which criticises Metz's Ubuntu moral theory and takes it as problematic in virtue of appealing to two moral values.

Second, and relatedly, it appears that there are now two, rather than one, non-instrumental values in Metz's Ubuntu theory. Alternatively, it is not entirely clear that we should still regard friendly relationships as the sole fundamental moral value a moral agent ought to promote. If the view that harmonious relationships are constitutive of the good and the claim that basic individual rights ought to be respected are accurate, then it seems that there are

14 See Daniel Bell (1993) for a clear articulation of the core commitments of communitarianism, according to which communitarianism can be taken to express certain claims: metaphysical, normative and methodological claims. The metaphysical claim concerns the communal nature of the self; the normative claim is about community as the fundamental value and the methodological claim relates to the importance of communal context in moral and political reasoning.

15 Or, as Sandel puts it, the right as "unconditionally prior to the good" or "justice as having a moral primacy" or "justice as justificatory prior" (1982: 18-19). 
two normative aims worth pursuing... it is worth pointing out that in the original statement of the ethical principle it seems that the moral agent is obliged to do the good - that is, promote harmonious relationships - everywhere. Now, it appears that sometimes the good is not worth doing. More importantly, the moral agent within the Ubuntu moral system has moral reasons to refrain from doing the good, and these reasons derive not necessarily from her valuation of community, but from facts about some inherent value in the individual that is, specific entitlements the protection of which assures the individual's well-being. So, although the theory still retains its commitment to the view that morality is other-regarding, it seems to imply that there is some non-instrumental value inherent in individuals rather than relationships, and this value is worth pursuing for its own sake...and further, not only does the theory in its more recent appearance equally prize two distinct moral values, but it also prizes two competing - insofar as they are potentially conflicting - non-instrumental values. (Oyowe 2013: 107)

The point here is that Metz's Ubuntu moral theory appeals to two distinct values that are difficult to reconcile; or even downright irreconcilable. Recall that part of the reasons why Metz takes the incorporation of a deontological constraint in his Ubuntu moral theory to be necessary, is his recognition that the goal of upholding individual freedom and human rights may be undermined by the goal of achieving harmony; or the goal of achieving harmony may sometimes clash with the aim of upholding individual freedom and human rights. It may be the case that in order to achieve harmony what needs to be done is for a doctor to kill an innocent, relatively healthy individual and distribute her harvested organs to three others who would otherwise die without them (Metz 2011: 540). But clearly in doing this one is sacrificing the freedom and right of the relatively healthy individual for the interests of the others and for harmony. Stated differently, in killing an innocent so as to achieve harmony, one is satisfying one value (that of harmony) in favour of another (individual freedom and human rights). The deontological constraint is meant to prevent this. But in giving space to the deontological constraint to breathe, one may in this case refrain from sacrificing the right of the relatively healthy individual for the interests of the others and for harmony. But in doing this one has failed to give effect to the value of harmony. That is, one is satisfying the value of individual freedom and human rights in favour of the value of harmony. One should add that the problem is not just that these values conflict, it is that a moral agent that finds herself in the situation of a moral choice and has to decide which value to take up, may be frustrated since she can't possibly act on both simultaneously.

Clearly, Metz is caught here in a dilemma and one may ask how he got trapped in it. Oyowe seems to suggest that Metz entangled himself in this web because of his desire in trying to present an Ubuntu moral theory that avoids the charge of majoritarianism or collectivism. He thinks that the attempt is unsuccessful because it "is like attempting a trick the aim of which is to eat one's cake and have it" (2013: 104). I agree with Oyowe but I want to suggest that Metz's desire and attempt give effect to some deeper motivation; the motivation that seeks to align some worldview 
with some ideal - the ideal that constructing or interpreting a moral theory in ways that make such a theory consistent with a particular paradigm, is desirable. Stated differently, the ideal driving the motivation to avoid the charge of collectivism, which will bedevil an Ubuntu moral theory if the deontological constraint is not introduced in order for it to avoid the charge, is one that is biased towards the Western liberal paradigm of prioritising the right over the good, namely, one that takes individual freedom and human rights as espoused by the liberal tradition in the West as better and desirable to the communitarian paradigm (that may be found in communities across sub-Saharan Africa) and espoused by Ubuntu sensitive values. It is this ideal that warrants my description of Metz as a psychological associate or WU insofar as he believes that there is a one "superior" Western paradigm, and he is committed to evaluating the merits of other cultures and life-experiences in terms of this one "superior" Western paradigm.

I now want to consider some objections that can be raised for my project. However, before I do that let me summarise briefly the main ideas presented thus far. Along the way to arriving at his favoured principle of Ubuntu and in developing his version of an Ubuntu-inspired moral theory, Metz thought it was necessary to introduce some deontological constraint that will delimit and forbid the sacrificing of individual freedom and rights in the pursuit of some communal values of harmony and relationships. But by making this move, Metz implicitly commits himself to the view that it is imperative to interpret and in fact circumscribe any moral theory or practice by respect for individual freedom and rights. ${ }^{16}$ Given that the priority of the value of individual freedom and human right over other interests, particularly those that are communal, is largely Western, Metz's introduction of the deontological constraint to bind and shackle the "excesses" of communal-sensitive practices can be interpreted as amounting to viewing African culture, values and philosophy from the lenses or prism of the Western world, both generally and particularly generally, in suggesting that African cultures and life-experiences must conform to some "superior" paradigm of the West, and particularly, in signifying that such conformity is necessary if they are to be desirable or respectable. Because Metz's presentation of Ubuntu is culturally imperialistic in virtue of constructing Ubuntu to be sensitive to ideals and paradigms that are predominantly of the West, he is a WU. However, because his cultural imperialism does not purposefully seek to denigrate or depreciate Ubuntu (or African philosophy or cultures and life-experiences) as inferior, he is only but an "intellectual admirer".

16 In pointing out that Metz's Ubuntu-inspired moral theory is culturally imperialistic because he interprets and circumscribes the theory by respect for individual freedom and rights, I am thereby not suggesting that freedom and rights are not important or valuable. I am merely pointing out what is going on in his analytic normative ethical theorisation, and the sorts of motivations that may be attached to his construction of an Ubuntu moral theory. 


\section{SOME OBJECTIONS AND RESPONSES}

In this section I present two related objections to my project, which I then respond to. The first objection is that my criticism of Metz falsely presents a choice between extreme individualism and extreme collectivism. The second has to do with the fact that my discussion of Western communitarianism and liberalism presents a distinction that is overdrawn. ${ }^{17} \mathrm{I}$ begin with the second objection.

The objection that I have offered an overdrawn distinction in my discussion of Western communitarianism and liberalism points to something deeper about the communitarian and liberal debate. Perhaps this distinction is not very sharp, particularly in the context of two things: firstly, the difficulty of identifying "the community" without invidious exclusion in multicultural societies; and secondly, the various attempts to balance the rights of individuals and those of communities. I do not think that the difficulty in demarcating community suggests that the distinction between communitarianism and liberalism is misleading. To hold this view is to suggest that those that have been involved in the communitarianism and liberalism debate have been wasting their time in a vacuous debate, or that the debate never happened. On a linguistic level, communitarianism is different from liberalism - they both mean different things. This difference is independent of the fact as to whether we can practically distinguish communitarianism from liberalism in a multicultural society. In any case, the mere fact that they have been attempts to balance the rights of individuals and those of communities suggest, to me, that there is recognition of the difference between individual rights and rights of communities. This difference, one could argue, suggests that communitarianism (which focuses on communal rights) and liberalism (which focuses on individual rights) represent two different paradigms. ${ }^{18}$

Now to the first criticism, which simply states that my position that Metz's presentation of Ubuntu is culturally imperialistic, is wrongheaded. It is wrongheaded for two reasons: (a) it ignores the fact that certain sacrifices of individual dignity the critic reminds us could be said to ultimately lead to disharmony or negative harmony; (b) it discounts the fact that certain rights cannot always be maintained if they disadvantage a whole community. I agree that in practice certain sacrifices of individual dignity could lead to disharmony, such that we may need to circumscribe

17 I thank one of the two anonymous reviewers for raising these objections.

18 Elsewhere, I have discussed aspects of liberalism and communitarianism which, I think, allows us to maintain a substantive distinction between both worldviews and paradigms (Etieyibo 2011: 1-26). The central theses I advanced in the paper is that (a) both an individualistic worldview (IW) and a communitarian worldview (CW) embody the same goal - the flourishing or wellbeing of citizens (i.e. the individuals that make up a body polity); (b) certain virtues are integral to such flourishing; (c) some praiseworthy civic virtues are affirmed by both IW and CW; (d) although both IW and CW affirm similar civic virtues, they have different foundations; and (e) the foundation of $\mathrm{CW}$ seems to undermine the very same virtues it seeks to uphold and for this it breaks down community. 
these sacrifices if we are interested in maintaining harmony. I also agree that insofar as we are keen on communal harmony, certain rights may have to be circumscribed if they disadvantage the entire community. However, this criticism ignores an important aspect of my project. I am not arguing in the abstract that sacrifices of individual dignity that lead to disharmony cannot or ought not be circumscribed, or that if certain rights disturb the harmony of the community, they should not be curtailed. What I am arguing is that in the particular instance of Metz's presentation of Ubuntu, the introduction of the deontological constraint simply does not entertain the possibility that some rights that disturb the harmony of the community may be abridged. Without qualification, the deontological constraint in Metz's version of an Ubuntu-inspired moral theory simply prohibits in whatever circumstances the sacrificing of individual freedom and rights in the pursuit of some communal values of harmony and relationships.

\section{CONCLUSION}

This paper is generally about African philosophy in the eyes of the West. I have pursued the thesis that some approaches to doing African philosophy can be considered culturally imperialistic in general, and that Metz's brilliant presentation of Ubuntu as an African moral theory is paradigmatic of this way. By way of concluding I would like to make two related remarks - the first, very briefly, and the second, a bit more detailed.

My first remark is that in proposing that Metz is a psychological associate or WU, I may be taken to suggest that the deontological constraint he introduces into his version of an Ubuntu-inspired moral theory, is unnecessary. If the constraint pulls his moral theory apart by presenting us with two moral values which are in conflict, then perhaps a truly communitarian commitment will suggest that one should let go of a reconciliation project that tries to fit in individual freedom and human rights with harmony or communitarian values and interests. This consideration is further advanced by my second remark.

It is important to emphasise that although Metz's version of an Ubuntu-inspired moral theory is exemplary of culturally imperialistic tendencies, his approach seems consistent with the spirit of scholarship. Scholars, and in particular philosophers, are brilliant at interpreting a theory, philosophical work or ideas that belong to a different epoch in the context of modern ideas, experiences and values. Thus, one may interpret some of Plato's dialogues or Kant's moral theory in the context of our modern world and show that the ideas of these past philosophers are not only relevant in today's world but consistent with some new and important thinking. But there would certainly be a limit to such interpretation. Thus one may be entitled to be restless if confronted with an interpretation that is stretched to breaking point and beyond reasonable imagination, no matter how brilliant such interpretation is. 
For example, one may legitimately worry if confronted with a secular interpretation of St Thomas Aquinas' philosophy, namely, an interpretation that makes God disappear from his philosophy. My point here is that, notwithstanding the fact that Metz's project in getting to his Ubuntu moral theory is consistent with the spirit of scholarship, one may worry whether it is not an interpretation that is stretched to breaking point. For his intentions may seem genuine - he wants to defend a version of Ubuntu that is impervious to the charge of collectivism. But perhaps Ubuntu does not need to be rescued from such charge. Maybe Ubuntu as a communitarian theory and as practised across sub-Saharan Africa prioritises harmony or the community over individual freedom and rights - and therefore is collectivistic.

Often, one motivation for the interpretation of a philosopher's ideas in the context of modern values and experiences is to protect the philosopher and his ideas against the worry of anachronism. But for me this may be doing too much. If the philosopher's ideas are anachronistic, they are anachronistic and perhaps should be left so. After all, philosophers are not omniscient; they are fallible. To interpret their ideas in ways which suggest that they are not anachronistic (if they are indeed anachronistic), is to suggest that they are omniscient and infallible. Similarly, if Ubuntu is collectivist and cannot respond appropriately to the enlightenment and modern demand of individual freedom and human rights, then let it be collectivist. After all, African people in the sub-Saharan belt who have circumscribed their practices by various intuitions and values are not omniscient and infallible. Before the enlightenment in the West people in the West did value less individual freedom and rights. Perhaps African people in the sub-Saharan belt, or Africans in traditional societies, as counterparts of those in the West before the enlightenment, also valued less individual freedom and rights and this is reflected in tendencies or themes and values that are associated with talk of Ubuntu and cognate terms that are prevalent in their worldview.

Here is perhaps where one needs to pay particular attention to Kwasi Wiredu's admonition in respect of comparison between African thought and Western thought. In the article, "How not to compare African thought with Western thought" Wiredu cautions practitioners of African philosophy to guard against uneven and incongruent comparison between African philosophy and Western philosophy, both in terms of subject matter and history (1984: 157-58). Wiredu's point is that if one thinks it is legitimate to compare African philosophy and Western philosophy, one must compare periods with periods and subject matter with subject matter. For example, it would be an incongruous comparison if one were to compare ancient African philosophy with modern Western philosophy. That seems to be part of what is going on with Metz's version of an Ubuntu-inspired moral theory. ${ }^{19} \mathrm{He}$ seems to be looking at

19 For dissimilar motivations and in different degrees Magobe Ramose has criticised Metz for not taking into account Wiredu's admonition of how not to compare African thought with Western thought (2007: 352). 
Ubuntu within the more modern and "refined" Western ideas of individual freedom and human rights, and trying so hard to fit the former into the latter at all cost. Perhaps what he should be doing, if he is interested in some comparison or fitting exercise and think this is legitimate, is to look at Ubuntu within the Western ideals pre the enlightenment. ${ }^{20}$

\section{REFERENCES}

Appiah, K.A. 1992. In my father's house: African in the philosophy of culture. London: Methuen. Bell, D. 1993. Communitarianism and its critics. Oxford: Clarendon Press.

Diop, C.A. and Okpewho, O.O. 1981. The search for a philosophy of African culture. Cahiers d'Etudes Africaines, 84: 587-602.

Du Bois, W.E.B. 1903. The souls of black folk. Penn State Electronic Classics Series Publication (2006). Pennsylvania: Pennsylvania State University.

Du Bois, W.E.B. 1935. Black reconstruction: An essay toward a history of the part which black folk played in the attempt to reconstruct democracy in America, 1860-1880. New York: Harcourt, Brace and Company.

Etieyibo, E. 2011. The self, individual moral responsibility and community. Testamentum Imperium 3:1-26.

Etieyibo, E. 2015. The question of cultural imperialism in African philosophy. In Atuolu Omalu: Some unanswered questions in contemporary African philosophy. Edited by J.O. Chimakonam. Lanham, Maryland: University Press of America, pp.147-170.

Eze, M.O. 2010a. The politics of history in contemporary Africa. New York: Palgrave Macmillan.

Eze, M.O. 2010b. Intellectual history in contemporary South Africa. New York: Palgrave Macmillan.

Hesein, I. 2010. African philosophy in globalizing world: A particularist perspective. Sofia: An African Journal of Philosophy 12(2): 15-21.

Janz, B. 2007. African philosophy. In The Edinburgh companion to twentieth century philosophies. Edited by C.V. Boundas. Edinburgh, Edinburgh University Press, p. 689.

Metz, T. 2007a. Toward an African moral theory. Journal of Political Philosophy 15(3): 321-341.

Metz, T. 2007b. Ubuntu as a moral theory: Reply to four critics. South African Journal of Philosophy 26(4): 369-387.

Metz, T. 2010a. Human dignity, capital punishment, and an African moral theory. Journal of Human Rights 9: 81-99.

Metz, T. 2010b. African and Western moral theories in a bioethical context. Developing World Bioethics 10(1): 49-58.

Metz, T. 2011. Ubuntu as a moral theory and human rights in South Africa. African Human Rights Law Journal 11(2): 532-59.

20 How would an examination of Ubuntu within the Western ideals pre the enlightenment look? I confess I have no idea at this point. 
Metz, T. 2012a. African conceptions of human dignity: Vitality and community as the ground of human rights. Human Rights Review 13(1): 19-37.

Metz, T. 2012b. Developing African political philosophy: Moral-theoretic strategies. Philosophia Africana 14(1): 61-83.

Metz. T. 2012c. Ethics in Africa and in Aristotle: Some points of contrast. Phronimon 13(2): 99117.

Metz, T. 2014. African values, human rights and group rights: A philosophical foundation for the Banjul Charter. In African legal theory and contemporary problems: Critical essays, vol. 29. Edited by O. Oche Onazi. Springer, 2014, p.131-51.

Momoh, C.S. 1985. African philosophy: Does it exist? Diogenes (International Council for Philosophy and Humanistic Studies), Summer, 130: 73-104.

Oguejiofor, J.O. 2007. The enlightenment gaze: Africans in the mind of Western philosophy. Philosophia Africana 10(1): 31-36.

Onyewuenyi, I.C. 1991. Is there an African philosophy? In African philosophy: The essential readings. Serequeberhan. Minnesota: Paragon House, pp. 29-46.

Oruka, H.O. 1975. The fundamental principles in the question of African philosophy. Second Order: An African Journal of Philosophy 4(1): 44-55.

Oyowe, A. 2013. Strange bedfellows: Rethinking Ubuntu and human rights in South Africa. African Human Rights Law Journal 13: 103-124.

Ramose, M.B. 2007. But Hans Kelsen was not born in Africa: A reply to Thaddeus Metz. South African Journal of Philosophy 26(4): 352.

Sandel, M. 1992. The procedural republic and the unencumbered self. In Communitarianism and individualism. Edited by S. Avineri and A. De-Shalit. Oxford: Oxford University Press, pp. 18-19.

Taylor, C. 1985. Philosophy and the human sciences: Philosophical papers 2. Cambridge: Cambridge University Press, pp. 187-210.

Van Hook, J.M. 1997. African philosophy and the universalist thesis. Metaphilosophy 28(4): 385-396.

Wiredu K. 1972. On an African orientation in philosophy. Second Order: An African Journal of Philosophy 1(2): 3-13.

Wiredu, K. 1984. How not to compare African thought with Western thought. In African philosophy. Edited by R.A. Wright. Lanham: University of America Press. 